Religious Studies (2012) 48, 403-414 C Cambridge University Press 2012

doi:10.1017/S0034412512000030

\title{
Understanding omnipotence
}

\author{
KENNETH L. PEARCE \\ School of Philosophy, University of Southern California, Mudd Hall of Philosophy, \\ 3709 Trousdale Parkway, Los Angeles, CA 90089-0451, USA \\ e-mail: kpearce@usc.edu
}

\author{
ALEXANDER R. PRUSS \\ Department of Philosophy, Baylor University, One Bear Place \#97273, Waco, \\ TX 76798-7273, USA \\ e-mail: Alexander_Pruss@baylor.edu
}

\begin{abstract}
An omnipotent being would be a being whose power was unlimited. The power of human beings is limited in two distinct ways: we are limited with respect to our freedom of will, and we are limited in our ability to execute what we have willed. These two distinct sources of limitation suggest a simple definition of omnipotence: an omnipotent being is one that has both perfect freedom of will and perfect efficacy of will. In this article we further explicate this definition and show that it escapes the standard objections to divine omnipotence.
\end{abstract}

\section{Introduction}

God is traditionally taken to have among his attributes essential omniscience and essential omnipotence. Being omniscient, he knows everything, and being omnipotent, he can do everything. In both cases, however, the quantifiers need to be understood as restricted. An omniscient being doesn't know that $2+2=3$, and an omnipotent being can't make a square circle. A classical restriction is that an omniscient being knows everything that is true, while an omnipotent being can do everything that is possible (Aquinas, Summa Theologica I.25.3). This may be correct on the side of omniscience, but the side of omnipotence has problems.

Some philosophers have supposed that to be omnipotent is to be able to realize any possible action type. ${ }^{1}$ Call this property 'act-omnipotence'. Act-omnipotence fails as an analysis of omnipotence, not only because no being could possibly be 
act-omnipotent, but also because it fails to capture intuitions about what it would take for a being to be omnipotent.

There is a well-known reason why no being could be essentially act-omnipotent: in order to be act-omnipotent, a being would have to be able to realize the action type making a stone too heavy for one to lift. This is certainly a possible action type - a human being could make a stone that is too heavy for her to lift. However, a being who had once performed this action could no longer be act-omnipotent, since it would then not be able to lift the stone it had created. It follows that no being could be essentially act-omnipotent.

It is common to reply to this concern by suggesting that a being might be only accidentally act-omnipotent. However, this too is impossible, since no omnipotent being can realize the action type bringing it about that one knows one is not and has never been omnipotent. But by a modicum of self-reflection, human beings can come to know they are essentially limited in power.

Fortunately for defenders of omnipotence, act-omnipotence, in addition to being incoherent, fails to capture the ordinary notion of omnipotence. This is because failing is a possible action type and, therefore, an act-omnipotent being could fail. However, it is central to the ordinary notion of omnipotence that it is impossible that an omnipotent being should ever fail in anything it attempts.

One might attempt to address these concerns by restricting the quantification to action types compatible with the being's nature. ${ }^{2}$ Thus, we could say $x$ is an omnipotent being provided $x$ can realize any action type that it is logically possible for $x$ to realize. ${ }^{3}$ But this runs into the case of McEar who essentially has the property of not realizing any action type other than scratching one's ear. ${ }^{4}$ If McEar can scratch his ear, then by the above definition he is omnipotent: he can do anything that it is logically possible for him to do.

A different approach is not to quantify over action-types, but over contingent propositions, and say that an omnipotent being is one who can bring about any contingent proposition $p$. This has the advantage of overcoming the stone problem as well as the problem of knowing oneself not to be omnipotent. For if $x$ is essentially omnipotent, then the propositions $<$ There is a stone $x$ can't lift $>$ and $<x$ knows that $x$ is not and has never been omnipotent $>$ are impossible. ${ }^{5}$ And McEar does not count as omnipotent, since he cannot bring it about that it is raining, although $<$ It is raining $>$ is contingent.

Nonetheless, the bringing-it-about approach has two serious difficulties. The first is that it may be impossible to bring it about that someone else freely (or, at least, in a non-derivatively free way ${ }^{6}$ ) As, even when the proposition $<y$ freely As $>$ is contingent.

The second difficulty is that God's essential perfect goodness seems to prevent him from bringing about certain bad states of affairs, and yet God is traditionally accounted omnipotent. Formulating this difficulty is somewhat tricky, though. Since God exists necessarily, if God's perfect goodness entails that he will prevent 
a certain state of affairs, then that state of affairs will be impossible. For a counterexample here one seems to need a case of something that is so bad that God cannot bring it about, but yet not quite bad enough that God cannot allow it to happen. However, assuming that the distinction between causing and allowing is morally significant, it is very plausible that there will be such cases. And if $p$ reports such a case, then God will not be able to bring $p$ about, even though $p$ is contingent.

Let us go back to the drawing board for the moment. We have seen that attempts to define omnipotence in terms of what an omnipotent being can do tend to run into contradictions. We have also seen that it is central to the ordinary notion of omnipotence that there is something an omnipotent being cannot do: an omnipotent being cannot fail. The fact that we human beings are capable of failure is one way in which our power is limited. Sometimes we do not succeed in realizing the course of action we have decided on. There is also a second way in which our power is limited, and this is by limitations on our freedom of will. These limitations can be due to psychological compulsions, lack of awareness of the range of options, or insufficient knowledge, whether of reasons or of means. Someone who had no limitations on the freedom of his will or the execution of what he has willed would be omnipotent.

This leads us to a very simple definition:

(1) $x$ is omnipotent if and only if $x$ has perfect freedom of will and $x$ has perfect efficacy of will.

The definition involves two concepts in need of further comment: perfect freedom of will and perfect efficacy of will. We will take them in the opposite order.

\section{Efficacy}

Efficacy of will is the ability to realize what one wills. Plausibly, then:

(2) $x$ has perfect efficacy of will if and only if $(p) \square((x$ wills $p) \rightarrow$ $(x$ intentionally brings about $p)) .^{7}$

This account has the interesting consequence that perfect efficacy of will is always an essential property. ${ }^{8}$

Unfortunately, (2) has a difficulty with an elaboration of the McEar story. Suppose that, additionally, it is impossible that McEar wills anything other than scratching his ear, but that necessarily if he wills the scratching, he intentionally brings it about that he scratches. Then, if $p$ is anything other than $<$ McEar scratches his ear $>$, then, necessarily, $(x$ wills $p) \rightarrow(x$ intentionally brings about $p)$ holds trivially due to its antecedent being false. But if $p$ is $<$ McEar scratches his ear $>$, then when $x$ wills it, $x$ intentionally brings it about. 
The simplest line of response to this objection would be to claim that McEar is impossible. Edward Wierenga has objected to the original McEar case that, since McEar is described as embodied, it is extremely implausible to suppose that he could not survive a change to his body which would allow him to take some other action (Wierenga (1983), 375). However, as Erik Wielenberg has shown, it is possible to construct McEar-style cases involving immaterial agents whose limitations look suspiciously similar to the limitations traditionally attributed to God in virtue of, for instance, his necessary moral perfection (Wielenberg (2000), 29-31). It is not difficult to see how the same strategy could apply here. Furthermore, even without this further modification, our modified McEar seems more likely to be possible than the original McEar, for two reasons. First, our McEar suffers a psychological, rather than physical, limitation. We know about a wide variety of psychological limitations which exist in the actual world, so it seems possible that there could be a being - perhaps even a human - limited in the way our McEar is. Furthermore, psychological properties are very important to personal identity, so it is not implausible to suppose that there could be a being who had these limitations essentially.

Furthermore, less radical examples than McEar can be given. There surely are things that it is logically impossible for a human (or cat) to do but the inability to do which marks an agent as not being omnipotent. Creating all material reality or contemplating all necessary truths might be examples. Imagine, then, a superpowerful human (or cat) that can do everything that it is logically possible for her to do. Since such a human (or cat) wouldn't be able to create all material reality or contemplate all necessary truths, she wouldn't be omnipotent, and adding that she, like modified McEar, also couldn't will these things would surely not help.

Granting that modified McEar (or a being like him in the relevant respects) is possible, one might bite the bullet and admit that McEar has perfect efficacy, and say instead that he lacks omnipotence because he lacks perfect freedom: his will is severely constrained. However, one might worry about what would happen if, per impossibile, McEar were to will something else - say that the Earth be destroyed by a stray comet (cf. Wielenberg (2000), 40-42). If, in this case, McEar's will would be frustrated, then it seems that McEar falls short of omnipotence not only with respect to his freedom, but with respect to his efficacy.

Thomas Aquinas, when discussing the question whether God's power is limited by the fact that God cannot do evil, suggests that God may have this sort of counterpossible power:

Nevertheless, the Philosopher says (Topic. iv, 3) that God can deliberately do what is evil. But this must be understood either on a condition, the antecedent of which is impossible - as, for instance, if we were to say that God can do evil things if He will. For there is no reason why a conditional proposition should not be true, though both the antecedent and consequent are impossible: as if one were to say: 'If man is a donkey, he has four feet.' (Summa Theologica I.25.3 Reply 2) 
Definition (2) does not require an agent to have counterpossible power in order to be perfectly efficacious. If, therefore, we wish to hold that McEar lacks perfect efficacy on account of his lack of counterpossible power over comets, a modification of (2) is required. The following definition suggests itself:

(3) $x$ has perfect efficacy of will if and only if $(p) \square((x$ wills $p) \square \rightarrow$ ( $x$ intentionally brings about $p$ ))

where ' $\square \rightarrow$ ' is a subjunctive conditional.

On Lewis-Stalnaker semantics, $\square(p \rightarrow q)$ holds if and only if $\square(p \square \rightarrow q)$ holds. ${ }^{9}$ Thus, if Lewis-Stalnaker semantics is correct and $\mathrm{S}_{5}$ holds, (2) and (3) are equivalent. As a result, if (3) is to express a stronger condition than (2), we must reject Lewis-Stalnaker semantics in favour of a view of conditionals on which some counterpossibles are true and others are false (on Lewis-Stalnaker semantics, they are all true). Such a view will allow us to hold that McEar is not perfectly efficacious, since it is false that were he to will to scratch his nose, he'd scratch his nose.

Since intuitively some counterpossibles are true, say that if a man were a donkey, he'd have four legs, and some counterpossible are false, say that if a man were a donkey, he'd have eight legs, we have reason to opt for a semantics that allows for some counterpossibles to be false. Furthermore, much philosophical discourse presupposes that some counterpossibles are true and others are false: many of the propositions debated in philosophy are matters of necessity, yet we often make (and debate) claims about what things would be like if our opponents' views were correct (see Merricks (2003), 5). Nevertheless, some philosophers are quite attached to the Lewis-Stalnaker semantics. These philosophers will still be able to deny that McEar is perfectly efficacious provided that they can distinguish between $p \square \rightarrow q$ being trivially true on account of the impossibility of $p$ and $p \square \rightarrow q$ being non-trivially true. This would lead to the following definition:

(4) $x$ has perfect efficacy of will if and only if $(p) \square($ it is non-trivially true that: ( $x$ wills $p) \square \rightarrow(x$ intentionally brings about $p))$.

In sum, we commend definition (3) to those philosophers who hold that some counterpossibles are false, but to those who hold that all counterpossibles are true, we commend definition (4). For the sake of simplicity, in what follows, we will use definition (3) and assume, as seems likely to us, that there are false counterpossibles. However, nothing essential to our account hinges on this.

Note that (3) is a very strong efficacy claim. On this account, a perfectly efficacious being has to be such that were it to will that some circle is a square, it would bring it about that some circle would be a square. Moreover, the perfectly efficacious being would be such that were it to will that $2+2=4$, it would bring it about that $2+2=4$. It is not clear to us that this is absurd. In fact, plausibly, it 
highlights just what a strong property omnipotence is. However, if one is convinced that such claims are just unintelligible, one can restrict the quantifiers to contingent propositions and get:

(5) $x$ has perfect efficacy of will if and only if $(p) \square(p$ is contingent $\rightarrow$ ( ( $x$ wills $p) \square \rightarrow(x$ intentionally brings about $p))$ )

Omnipotence is the property of being all powerful, and we are here providing an analysis of omnipotence which makes essential use of a conditional property, namely, perfect efficacy. In recent years, especially since the work of C. B. Martin on the conditional fallacy (Martin 1994), many philosophers have become quite sceptical of conditional analyses of dispositions, powers, and abilities. However, the standard worries about conditional analyses do not apply to the present case.

One famous objection to conditional analyses of ability which clearly does not apply here is Austin's golfer (Austin (1961), 218 n. 1). Austin's objection is that many human abilities, like the ability to sink a putt from a certain distance, are chancy: that is, one may have the ability to perform an action despite sometimes trying and failing to perform it. Simple conditional analyses wrongly rule out these chancy abilities. However, a being with chancy abilities would certainly not be omnipotent. As a result, it is a virtue and not a vice of the efficacy condition that it rules out chancy abilities.

Martin identified two additional difficulties for conditional analyses of dispositions (and powers or abilities) which have come to be known as 'finkish dispositions' and 'finkish lacks of dispositions' (Lewis 2003). The first type of case is meant to show that the truth of the conditional is not necessary for the possession of the dispositional property, and the second is meant to show that the truth of the conditional is not sufficient for possession of the property. The argument from finkish dispositions runs as follows: to say that $x$ is soluble in liquid water provided that $x$ would dissolve were $x$ placed in liquid water is too strong - it could, for instance, be that some body of water is equipped with a device that freezes it whenever $x$ is placed in it. In such a case, $x$ is said to be finkishly disposed to dissolve in liquid water: $x$ has the disposition to dissolve in water, but if it were placed in water it would not dissolve. Consequently, instead of saying that $x$ would dissolve, we should say that $x$ would be disposed to dissolve. A being whose abilities were finkish, like a being whose abilities were chancy, would not be omnipotent. Again, (3) is correct to rule out this case.

An entity exhibits a finkish lack of a disposition when the relevant counterfactual holds aberrantly. For instance, suppose that $x$ is a pentagonal steel ring, but by an odd law of nature, whenever a pentagonal steel ring is placed in water, it instantly turns into sugar. The counterfactual that $x$ would dissolve if placed in water holds, but the dissolving doesn't come from the placement in water in the right way. Despite the truth of the counterfactual, the ring is not disposed to dissolve in water. It is therefore said to finkishly lack this disposition. 
Our definitions of perfect efficacy already incorporate an in-the-right way component in the consequent of the conditional: it is specified that the agent intentionally brings about $p$. But $x$ intentionally brings about $p$ only if $x$ brings $p$ about in non-aberrant fulfilment of $x$ 's willing $p$. Accordingly, our definition correctly rules out those cases in which a being finkishly lacks perfect efficacy. ${ }^{10}$

There is still a subtle worry, which perhaps won't worry everyone. A person might have two simultaneous acts of will, willing $p$ and willing $q$ at the same time. This is easy when $p$ and $q$ are distinct: one can simultaneously will that the match be struck and that the match come afire. But perhaps someone could engage in two simultaneous acts of will with the very same propositional object. ${ }^{11}$ We do not know if this is possible. But if it is, one might have the following worry: the definitions of perfect efficacy fail to tell us that both of the acts of will are efficacious - perhaps one is efficacious and the other fizzles out in some way. This scenario appears to be incompatible with perfect efficacy. Perfect efficacy would require distinct simultaneous acts of will to each be efficacious.

If such simultaneous acts of will are possible, then a modification to our conditional accounts will be needed. We will give this in the case of (3), and the other accounts can be modified similarly:

(6) $x$ has perfect efficacy of will if and only if $(p) \square((x$ wills $p) \square \rightarrow$ $(A)(A$ is an act of $x$ 's willing $p \rightarrow A$ is efficacious $)$ )

Philosophers suspicious of the notion of token 'acts of will' will do well to stay with the unmodified versions.

\section{Freedom}

Perfect efficacy of will is a necessary condition for omnipotence: a being whose will could be frustrated would not be omnipotent. However, it is not a sufficient condition. It is not possible that my desk's will is frustrated, but this is only because, necessarily, my desk never wills anything. Granted, in the case of my desk, the requisite counterpossibles about what would happen were the desk to will it come out false (or trivially true), but this cannot be used to deal with every case of restriction of will. For instance, a being who suffered from what Gary Watson has called 'volitional disability' could not be omnipotent, even if it had perfect efficacy of will (Watson (2004), sect. 3). According to Watson, some phobics are so paralysed by their fears that they are not only incapable of acting in certain ways; they are incapable even of trying to act in those ways. A being who suffered this sort of impairment would not be omnipotent, no matter how efficacious its will.

Another phenomenon which is sometimes thought of as an impairment of the will is akrasia. For instance, we might imagine that McEar manages to consider the possibility of ceasing to scratch his ear, and conclude that it would be good if 
he did. Furthermore, it might be true that if he willed to stop scratching his ear, he would stop. Nevertheless, the desire to scratch his ear might be so strong that he can't manage to will to stop. A being who had this kind of experience could not be omnipotent. ${ }^{12}$

Some philosophers, such as Descartes and Albritton, claim that the idea of a restriction of the will is incoherent (Albritton (1985)). Albritton claims that it is part of the concept of a will that all wills are perfectly free. However, even Albritton admits that there are cases in which we are unable to try to act. Albritton says that he cannot try to wiggle his teeth because, 'Given what [he] vaguely think[s] about human teeth... [he is] not inclined to count anything [he] might conceivably do now as "trying to wiggle [his] teeth" ' (Albritton (1985), 245). In Albritton's examples it seems that the reason the subject cannot try to perform the action is because the subject has an accurate conception of the efficacy of its will: Albritton cannot try to wiggle his teeth because he correctly conceives of himself as the sort of being for whom such an action is not an option. However, the conception would be just as effective in limiting what a being could try to do even if the conception were incorrect. Thus a being with perfect efficacy of will might not be omnipotent as a result of being unable to conceive of itself as bringing about certain propositions, although it would bring them about if it so willed. ${ }^{13}$ According to Albritton, this is no hindrance to freedom of will. Nevertheless, it certainly is a hindrance to perfect freedom in the sense required for omnipotence.

Cases where freedom is constrained by an inability to conceive a possibility, unlike cases of akrasia or volitional disability, are not always cases of something going wrong in the agent. It is not a disability that Euclid couldn't will to write an article expounding General Relativity, that Cleopatra couldn't will to speak Esperanto, and that Leonardo da Vinci couldn't will to make an impressionistic painting. But in all cases, this was nonetheless an imperfection in their freedom.

Freedom is required for omnipotence. Naively we might suppose that what was required was simply that an omnipotent being should be able to will anything. However, if perfect efficacy of will is a necessary condition of omnipotence, then this suggestion would render omnipotence incoherent. This is because, for any being $x$, there are certain propositions such that it is logically impossible that $x$ bring them about. Such propositions include necessary falsehoods, the proposition that $x$ never existed, and perhaps also propositions about which actions agents other than $x$ freely perform. By the distribution axiom of modal logic it is provable that, if $x$ has perfect efficacy of will, then it is logically impossible that $x$ should will any of these propositions: since it is impossible that anyone bring it about that $2+2=3$, and since an omnipotent being's will could never be frustrated, it must be impossible that an omnipotent being should will that $2+2=3$.

Let us call the inability to will a certain proposition a limitation on the will, and any limitation which diminishes the agent's freedom a constraint on the will. What 
the above shows is that if every limitation is a constraint, then omnipotence, as we have defined it, is incoherent. Fortunately, there is good independent reason to suppose that some limitations are not constraints. One example of a limitation which is not a constraint is the limitation present in so-called 'Luther cases'. A number of philosophers have supposed that Martin Luther was both free and morally responsible in his decision not to recant, and yet correctly identified some sort of genuine limitation on his will when he uttered the words 'I can do no other' ${ }^{14}$ Gary Watson identifies a related phenomenon in the 'impossibility' Jane Austen's character Elizabeth Bennett finds in marrying Mr Collins (Watson (2004), 106-110). Elizabeth is actually said to pity her neighbour Charlotte Lucas, who does not experience this limitation on her willing.

While there is a great deal of disagreement about what exactly is the correct analysis of this sort of case, there is one point on which there seems to be wide agreement among philosophers: a limitation on the will is not a constraint if that limitation arises from the agent's character and/or choices in the right way. There is disagreement as to how we should understand character, and how exactly the limitation must arise from character and/or choices in order for it not to be a constraint, but most accounts of non-constraining limitations seem to have this general structure. On Harry Frankfurt's view, a limitation is not a constraint when the limitation is self-imposed as a result of what the agent cares about. According to Bernard Williams, a limitation is not a constraint when it arises from the agent's evaluation of the situation. Finally, according to many libertarians, including Robert Kane, a limitation is not a constraint when the limitation is due to the 'self-forming' actions of the agent - that is, the agent has, by her own free choices, made herself the sort of person who cannot will this particular proposition.

Another point of commonality between these differing accounts is that they all require that the agent strongly endorse the limitation of its will. On Frankfurt's and Williams' accounts, the endorsement occurs at the time at which the limitation is in effect; on Kane's account, the limitation was endorsed in earlier free actions (Kane (1996), 73-75).

It is not our purpose here to defend a particular account of freedom. However, it seems to us that any plausible account of freedom, whether compatibilist or incompatibilist, will allow that some limitations on the will-limitations which proceed from the agent's character or choices in a certain way, or which the agent strongly endorses - are not constraints. Furthermore, since there are many things which it is not logically possible that a perfectly efficacious being should will, an omnipotent being's will would be subject to such limitations.

Perfect freedom requires perfect rationality. Someone lacking in rationality is suffering from a constraint on freedom. Now, either it is impossible for one to will what one knows for certain to be a necessary falsehood, or else it is possible, but it is always a failure of rationality. Thus, in the case of a being that is also omniscient, 
we should not see it as a constraint on freedom if the being is unable to will necessary falsehoods, or to engage in more subtly rationally inconsistent exercises such as willing that one had never existed or that one had never willed anything. In particular, if God is essentially omnipotent and necessarily existent, the proposition < There is a stone that no one can lift > is impossible, and there is no need for a perfectly free being to be able to will it. ${ }^{15}$

The coherence of the traditional view that God is essentially perfectly good can also be defended along these lines. A being who is perfectly good identifies with or endorses the highest of moral standards. ${ }^{16}$ This would have the effect of limiting, though not constraining, its will.

We can now say that $x$ has perfect freedom if and only if there are no constraints on $x$ 's will. A failure of perfect rationality, such as akrasia, is an example of a constraint that would prevent one from having perfect freedom.

Ignorance is often a constraint on freedom. In fact, it may well be that nothing short of omniscience will do for a perfectly free being's knowledge. It would be a constraint not to know something that is rationally relevant to deciding what to will. If I am deliberating whether to turn on the light, but do not know that pulling the switch would alert burglars, I am not perfectly free. In fact, just about every fact is relevant to some decision. For instance, whether it will be sunny on this day next year is relevant to deciding whether to announce sententiously to one's friends that it will be sunny on this day next year. One's ignorance on this point is a constraint, albeit a minor one. The last example suggests that full omniscience - including knowledge of contingent future facts - is required for perfect freedom, with the corollary being that Open Theism is incompatible with omnipotence.

Giving a full account of perfect freedom is beyond our skills. For one, there are probably constraints we have not thought of. For another, a full account of perfect freedom may require a solid account of freedom as such, and that is no mean task.

\section{Conclusions}

Omnipotence is perfect efficacy plus perfect freedom. This is a simple account that reduces omnipotence to two other important divine attributes that very plausibly are a part of the classical conception of God.

This account of omnipotence of course calls forth accounts of perfect efficacy and perfect freedom. We have sketched some plausible accounts of perfect efficacy. Giving an account of perfect freedom is an important question for future research. But even without a full account of perfect freedom, the puzzles about stones too heavy to lift or events that are morally intolerable can be handled. Such puzzles do not challenge perfect efficacy, but are rather challenges for perfect freedom. But reflection on the rationality involved in freedom shows that divine inability to will such things is compatible with perfect freedom. 


\section{References}

Albritton, Rogers (1985) 'Freedom of will and freedom of action', Proceedings and Addresses of the American Philosophical Association, 59, 239-251.

Aquinas, Sт Tномаs (1921) The Summa Theologica of St. Thomas Aquinas, Fathers of the English Dominican Province (tr.) (London: Burns Oates \& Washbourne).

Austin, J. L. (1961) 'Ifs and cans', in Austin, Philosophical Papers (Oxford: Oxford University Press), 205-232. Frankfurt, Harry (1982) 'The importance of what we care about', Synthese, 53, 257-272.

Geach, P. T. (1973) 'Omnipotence', Philosophy, 48, 7-20.

Kane, Robert (1996) The Significance of Free Will (Cambridge: Cambridge University Press).

La Croix, Richard R. (1977) 'The impossibility of defining “omnipotence"', Philosophical Studies, 32, 181-190.

LEWIS, DAVID (2003) 'Finkish dispositions', The Philosophical Quarterly, 47, 143-158.

Mann, William E. (1977) 'Ross on omnipotence', International Journal for Philosophy of Religion, 8, 142-147.

Martin, C. B. (1994) 'Dispositions and conditionals', The Philosophical Quarterly, 44, 1-8.

Merricks, Trenton (2003) Objects and Persons (Oxford: Clarendon Press).

Plantinga, Alvin (1967) God and Other Minds: A Study of the Rational Justification of Belief in God (Ithaca NY:

Cornell University Press).

Ross, James F. (1969) Philosophical Theology (Indianapolis: Bobbs-Merrill).

Sobel, JoRdan Howard (2004) Logic and Theism: Arguments for and against Beliefs in God (Cambridge: Cambridge University Press).

WATSON, GaRY (2004) 'Volitional necessities', in Agency and Answerability: Selected Essays (Oxford: Oxford University

Press), 88-122.

WielenberG, EriK J. (2000) 'Omnipotence again', Faith and Philosophy, 17, 26-47.

Wierenga, EdWARd (1983) 'Omnipotence defined', Philosophy and Phenomenological Research, 43, 363-375.

Williams, Bernard (1993) 'Moral incapacity', Proceedings of the Aristotelian Society, 93, 59-70.

\section{Notes}

1. This is the approach adopted by Geach (1973), and Sobel (2004), ch. 9, both of whom conclude that omnipotence, at least when combined with the rest of the traditional picture of God, is incoherent.

2. Sobel (2004), 365-367, proposes this idea, though he takes it as an alternative to omnipotence rather than an analysis of it.

3. Wierenga (1983) defends a similar analysis, though he quantifies over states of affairs rather than action types.

4. This example was introduced by Plantinga (1967), 170. The name 'McEar' is due to La Croix (1977).

5. An interesting consequence of this view would be that an omnipotent being has to be essentially omnipotent. For if $x$ is omnipotent but not essentially so, then $<x$ knows that $x$ is not omnipotent and has never been omnipotent $>$ is possible, and so $x$ would have to be capable of bringing it about. But, plausibly, an omnipotent being can't bring that about.

6. Libertarians can distinguish between two kinds of freedom. Non-derivative freedom is exercised in what Robert Kane calls 'self-forming actions' (Kane (1996), ch. 5), which are not causally determined by antecedent conditions. Derivative freedom is exercised when one's action is psychologically determined, but one's earlier non-derivatively free actions have made one relevantly responsible for the determining characteristics.

7. On the plausible assumption that all propositions exist necessarily, $(p) \square \varphi(p)$ is equivalent to $\square(p) \varphi(p)$. We adopt the convention of placing the quantifier outside the modal operator.

One might try to replace ' $x$ intentionally brings about $p$ ' with just ' $p$ ', but then we would have as a counterexample a being that has the essential property that God fulfils whatever the being wills. Such a being's will is not efficacious.

8. Our efficacy condition is similar to the analysis of omnipotence defended by Ross (1969), ch. 5 . However, for reasons to be discussed in the next section, we deny that this is a sufficient condition for omnipotence. Also, by using a conditional in place of Ross's biconditional, we avoid the problems raised by Mann (1977).

9. One direction is easy. The only worlds at which $p \rightarrow q$ is false are worlds where $p$ is true and $q$ is false; but at such worlds, $p \square \rightarrow q$ is false on Lewis-Stalnaker semantics. Therefore, $p \square \rightarrow q$ entails $p \rightarrow q$.

\section{CAMBRIDGE JDURNALS}


It follows from this that if $p \square \rightarrow q$ holds in every world, $p \rightarrow q$ also holds in every world. The other direction is also easy. If $\square(p \rightarrow q)$ at some world $w$, then it is true at $w$ that $q$ holds at every world at which $p$ holds, from which it follows that it is true at $w$ that $p \square \rightarrow q$. But if $\square(p \rightarrow q)$ is true at one world, it is true at every world, so $p \square \rightarrow q$ is likewise true at every world.

10. The being, mentioned in note 7 above, whose will is always fulfilled by God finkishly lacks perfect efficacy.

11. This is very easy in the case of external time if time travel is possible. I could go back to a time $t$ at which I am trying to lift a sofa, and help myself lift that sofa, and at $t$ there will be two distinct acts of willing that the sofa be lifted. But these two acts of willing are non-simultaneous with respect to internal or subjective time.

12. If akrasia involves having an unfulfilled higher-order volition, then no being who had perfect efficacy of will could be akratic.

13. This inability need not count against the being's perfect efficacy of will. It might be that the being has simply never thought of the proposition $p$, and, as a result, cannot will that $p$, or will that it should conceive of itself as being able to bring it about that $p$, or will that it should conceive of itself as conceiving of itself, etc. In other words, the being might be trapped by the 'Paradox of Inquiry' from Plato's Meno: if it knew what it was looking for, it would have no trouble finding it, but of course if it already knew what it was looking for it wouldn't be looking.

14. See Frankfurt (1982), 263-266; Albritton (1985), 246-247; Williams (1993), 61. For a survey of analyses of Luther cases, see Watson (2004), 100-106, 110-114.

15. At least assuming 'lift' here means bring about an upward motion of, rather than denoting some notion more closely tied to corporeality.

16. In fact, if, as some philosophers hold, moral norms are derived from rational norms then, since omnipotence entails perfect rationality, it will also entail perfect goodness.

\section{CAMBRIDGE JDURNALS}

